\title{
Correction to: Health and Education: Seeking an Explicit Place on the Agenda
}

\section{Correction to:}

Chapter 8 in: B. Harry, Childhood Disability, Advocacy, and Inclusion in the Caribbean, Palgrave Studies in Disability and International Development, https://doi.org/10.1007/978-3-030-23858-2_8

The original version of the book was inadvertently published with an error in the way the events were reported in this chapter. The chapter has now been corrected and approved.

The updated version of the chapter can be found at https://doi.org/10.1007/978-3-030-23858-2_8

(C) The Author(s) 2021 